\title{
Maternal Vitamin D Deficiency and Insufficiency - Prevelance and Effective Factors
}

\author{
Deha Denizhan Keskin ${ }^{1}$ \\ Turkey. \\ ${ }^{1}$ Department of Obstetrics and Gynecology, Ordu University of Medical Faculty, Education and Research Hospital, Ordu,
}

Received: 26 October 2018, Accepted 09 December 2018, Published online: 27 December 2018

(C) Ordu University Institute of Health Sciences, Turkey, 2018

\begin{abstract}
Objective: We aimed to reveal the prevalences of vitamin D deficiency and severe deficiency in pregnant women who applied for routine examination in our study.

Methods: Between January 2015 and January 2018, 635 healthy pregnant women who applied to our clinic for the first trimester routine pregnancy examination were included in the study. The age, place of residence, season in which the material was taken, 25 - OH vitamin D levels were reached. Vitamin D level under 10 $\mathrm{ng} / \mathrm{ml}$ was accepted as severe deficiency, $10-30 \mathrm{ng} / \mathrm{ml}$ insufficiency and $30-100 \mathrm{ng} / \mathrm{ml}$ normal.

Results: Vitamin D deficiency was detected in $58.1 \%$ and severe deficiency was found in $36.9 \%$, while vitamin D levels were normal in only $5 \%$ of the patients. Vitamin D levels were significantly lower in the 35 years old group $(95.8 \%-90.9 \%)(\mathrm{p}=0.03)$. There was no statistical correlation between the place of residence and vitamin $\mathrm{D}(94.6 \%-95.7 \%)(\mathrm{p}=0.529)$. We found abnormal vitamin $\mathrm{D}$ results in winter and autumn season $(98 \%-99.4 \%$ versus $89.4 \%-93.3 \%)(\mathrm{p}=0,000)$.

Conclusion: We observed that vitamin D deficiency and severe deficiency, which have serious maternal and neonatal effects, are quite common in our society $(95 \%)$. We are in the belief that how much decrease in negative maternal and perinatal outcomes have been observed with the 'Vitamin D Supplement Programme in Pregnancy' hold by T.C. Ministry of Health, via using 1200 IU vitamin D perday from 12 week of pregnancy until postpartum 6th month, by cross-sectional studies and if the first 6 year results are in positive direction, deficiency must be replaced according to age, season, and the geographic region with more effective methods.
\end{abstract}

Key words: Vitamin D, pregnancy, prevalence

Address for correspondence/reprints:
Deha Denizhan Keskin
Telephone number: +90 (505) 6055978
E-mail: dehadenizhankeskin@ @mail.com

DOI: $10.19127 / \mathrm{mbsjohs.474947}$

\section{Introduction}

Vitamin D is one of the fat-soluble vitamin and is first named in 1920. It is nowadays known as a steroid hormone, not a classical vitamin because it can be synthesized endogenously in the appropriate biological medium, Although it is known that the most important effect is on calcium-phosphorus metabolism and bone mineralization, it is also known to be associated with cancer (such as breast, ovarian, endometrium, gastrointestinal tumors, lymphoma), cardiovascular diseases, metabolic syndrome (hypertension and diabetes), infectious diseases, autoimmune diseases (multiple sclerosis, arthritis), musculoskeletal diseases (osteoarthritis), which are associated with many health problems 
(Barrett and McElduff, 2010; Iyidir and Altınova 2012).

Vitamin D is known to be synthesized in the skin by the effects of ultraviolet (UV) rays in $90-95 \%$. Dietary intake of fatty fish species, fish oil and vitamin D-containing preparations have little effect on vitamin D levels in the body (Fidan et al., 2014). Ergocalciferol (vitamin D2) is derived from plantderived ergosterol, and 7 - dehydrocholesterol (provitamin D3) is cholecalciferol (vitamin D3). Due to its biomolecular structure, the biological activity of vitamin D2 is 3 to 10 times lower than that of vitamin D3. Vitamin D, formed by epidermis with UV effect, binds to vitamin D binding peptide (DBP) and transported to the liver. In the liver by 25 alpha hydroxylation is converted to $25-\mathrm{OH}$ vitamin $\mathrm{D}$ (calcidiol). Although $25-\mathrm{OH}$ vitamin $\mathrm{D}$ is not biologically active, it is very important to show the level of vitamin $\mathrm{D}$ in the body thanks to its long half - life of 2 - 3 weeks. The $25-\mathrm{OH}$ vitamin D is converted to $1,25-\mathrm{OH}$ vitamin $\mathrm{D}$ (calcitriol), a biologically active form, by passing through the circulation and undergoing 1 alpha hydroxylation in the kidney under parathormone (PTH) control. 1,25 - OH vitamin D has a half - life of 4 - 6 hours and can not be used for measurement. Parathormone, hypocalcemia/phosphatemia, increases active metabolite conversion (Bikle, 2007; Meer et al., 2011; Mallah et al., 2011).

In order for fetal bone mineralization to take place in a healthy way during pregnancy, comprehensive adaptations to vitamin D and hence calcium metabolism occur. Approximately 25 - 30 grams of calcium passes through the fetus during pregnancy. Mother does that calcium balance which in favor of fetüs by increasing calcium absorption from the mouth (the most important effect), by increasing the kidney calcium uptake and by increasing calcium mobilization from the bone. In pregnancy placenta, amnion, umbilical cord, decidua, breast and fetal parathyroid secrete PTHrelated peptide (PTHrP) and the amount increases as pregnancy progress. Renal calcitol synthase increases with estrogen, prolactin, human chorionic somatotropin in addition to PTHRP (Kovacs and Kronenberg, 1997; Kent et al., 1991; Kovacs and Kronenberg, 2006).

Maternal vitamin $\mathrm{D}$ has been shown to be effective in fetal bone development as well as in dental, neuronal and fetal growth. In addition, normal vitamin $\mathrm{D}$ levels have been shown to reduce the incidence of diabetes (Pludowski et al., 2013).
We have seen in recent years that vitamin $\mathrm{D}$ deficiency has been studied in more detail in terms of causing severe maternal and neonatal problems, and in many health policies, strategies to prevent deficiency of maternal vitamin D (Kiely and Hemmingway, 2017).

We aimed to emphasize the importance of determining the prevalence of maternal vitamin $\mathrm{D}$ deficiency and its treatment

\section{Methods}

Ordu Provincial Health Directorate and Ordu University Medical Faculty Training and Research Hospital Clinical Practice Ethics Committee approvals were obtained (Date:26/04/2018, Number: 2018-87). Between January 2015 and January 2018, 635 healthy pregnant women who applied to the obstetrics clinics for the first trimester routine pregnancy examination were included in the study. Those who have chronic disease and / or metabolic disease, who use drugs effective on bone metabolism, are excluded from the study. Patients' age, place of residence, 25 - OH vitamin D levels obtained using Architect System, and the season in which the material was received were obtained from our hospital registry system.

25 - OH vitamin D level was $<10 \mathrm{ng} / \mathrm{ml}$, severe deficiency, 10 - $30 \mathrm{ng} / \mathrm{ml}$ insufficiency and 30 - 100 $\mathrm{ng} / \mathrm{ml}$ were normal. Patients were divided according to age groups as under and over 35; according to residence site as rural and urban; and to the season in which materials obtained as spring, summer, autumn and winter.

Statistical analysis of the data was performed using the SPSS 20 program. Student's t-test was used to compare numerical data, chi-square and Fisher Exact test were used to compare continous data. A P value $<0.05$ was considered statistically significant.

\section{Results}

The mean age of pregnancies was $28.9 \pm 5.34(18$ - 40). $66.8 \%$ of the patients were urban, and $33.2 \%$ were living in the rural area.

$25-\mathrm{OH}$ vitamin D insufficiency and severe deficiency were found to be $58.1 \%(369 / 635)$ and $36.9 \%(234 / 635)$ respectively, while only $5 \%$ $(32 / 635)$ of the patients was normal for vit D levels. Vitamin D insufficiency, severe deficiency and normal prevelances is showen in Table 1. 
Table 1: Vitamin D insufficiency, severe deficiency and normal prevelances.

\begin{tabular}{lcc}
\hline Insufficiency & $369 / 635$ & $58.1 \%$ \\
Severe Deficiency & $234 / 635$ & $36.9 \%$ \\
Normal & $32 / 635$ & $5 \%$ \\
\hline
\end{tabular}

Patients were divided into two groups as $<35$ years and $>35$ years according to age groups. The abnormal $25-\mathrm{OH}$ vitamin $\mathrm{D}$ results were found to be $95.8 \%$ in the < 35 age group and $>90.9 \%$ in the 35 years' age group. $25-\mathrm{OH}$ vitamin D level was significantly lower in the $<35$ years' age group $(\mathrm{p}=$ 0.03 ). Abnormal vitamin $\mathrm{D}$ ratio -age related is showen in Table 2.

Table 2: Abnormal vitamin D ratio - age related

\begin{tabular}{ccc}
\hline Age group & $\begin{array}{c}\text { Abnormal } \\
\text { patient } \\
\text { number }\end{array}$ & $\begin{array}{c}\text { Abnormal } \\
\text { patient ratio }\end{array}$ \\
\hline$<\mathbf{3 5}$ & 503 & $95.8 \%$ \\
$>\mathbf{3 5}$ & $\mathbf{1 0 0}$ & $\mathbf{9 0 . 9} \%$ \\
\hline
\end{tabular}

The rate of abnormal 25 - $\mathrm{OH}$ vitamin $\mathrm{D}$ values in urban and rural population was found to be close to each other $(94.6 \%-95.7 \%)$. There was no statistical correlation between the place of life and 25 - OH vitamin $\mathrm{D}$ values $(\mathrm{p}=0.33)$. Abnormal vitamin D ratio - residence related is showen in Table 3.

Table 3: Abnormal vitamin D ratio - residence related

\begin{tabular}{lcc}
\hline $\begin{array}{l}\text { Place of } \\
\text { residence }\end{array}$ & $\begin{array}{l}\text { Abnormal } \\
\text { patient number }\end{array}$ & $\begin{array}{c}\text { Abnormal } \\
\text { patient ratio }\end{array}$ \\
\hline Urban & 401 & $94.6 \%$ \\
Rural & $\mathbf{2 0 2}$ & $\mathbf{9 5 . 7 \%}$ \\
\hline
\end{tabular}

The abnormal 25 - OH vitamin D results were ranked according to the seasons as follows; Summer $89.4 \%$ - Spring $93.3 \%$ - Winter $98 \%$ - Autumn 99.4 $\%$. We found that abnormal $25-\mathrm{OH}$ vitamin $\mathrm{D}$ results were more common in winter and autumn ( $p$ $=0,000)$. Abnormal vitamin $\mathrm{D}$ ratio - season related is showen in Table 4.

Table 4: Abnormal vitamin D ratio - season related

\begin{tabular}{|c|c|c|}
\hline Season & $\begin{array}{l}\text { Abnormal patient } \\
\text { number }\end{array}$ & $\begin{array}{l}\text { Abnormal } \\
\text { patient ratio }\end{array}$ \\
\hline Summer & 147 & $89.4 \%$ \\
\hline Spring & 154 & $93.3 \%$ \\
\hline Winter & 144 & $98 \%$ \\
\hline Autumn & 158 & $99.4 \%$ \\
\hline
\end{tabular}

\section{Discussion}

Maternal vitamin D deficiency; composses the risk of vitamin D deficiency in neonates and also risk for infantile rickets. It is also emphasized that pregnancy is a critical period and fetal effects continue all the life time when the effects of vitamin $\mathrm{D}$ on fetal bone and neuronal development is taken into account. Complications such as low birth weight, skeletal problems, neonatal hypocalcemia, immunodeficiency, and type 1 diabetes in the newborn can occur in the newborn while poor results such as maternal sub/infertility, preclampsia, gestational diabetes and increased cesarean rate occur due to lack of vitamin D in the mother.

Vitamin D measurement is biochemically challenging. Different results can be obtained with different methods of analysis, with more than $10 \%$. Immunoassay (radio, manual, automated) and LCMS / MS (liquid chromatography-tandem mass spectrometry) are the most widely used methods. It is possible to perform healthier prevalence studies by standardizing the methods used worldwide (Ferrari et al., 2017).

We have taken the thresholds for our study according to a report published by the Ministry of Health in 2011. According to this report, 25 - OH D levels of $30 \mathrm{ng} / \mathrm{ml}$ are considered as threshold values in adults, which are not considered to cause parathyroid hormone elevation. Values between 10 and $30 \mathrm{ng} / \mathrm{ml}$ are considered to be inadequate and values below $10 \mathrm{ng} / \mathrm{ml}$ are considered to be severe.

The average maternal vitamin $\mathrm{D}$ concentration ranged from 5.2 to $52 \mathrm{ng} / \mathrm{mL}$ ( 13 to $130 \mathrm{nmol} / \mathrm{L}$ ) according to a review, which included studies from 1959 to 2014. Globally, vitamin D deficiency is present in 54\% of cases (threshold value of $20 \mathrm{ng} /$ $\mathrm{mL}$ ) and severe vitamin D deficiency is in $18 \%$ (threshold value of $10 \mathrm{ng} / \mathrm{mL}$ ) (Rajneeta et al., 2016).

In the study of USA, Australia, Middle East and South Asia, where the threshold values were $30 \mathrm{ng} /$ $\mathrm{ml}$ for failure and $20 \mathrm{ng} / \mathrm{ml}$ for severe deficiency, the prevalence of vitamin D severe deficiency was 26-98\%, while the prevalence of insufficiency was 66-100\% (Daphna, 2011). These data show how much the thresholds affect the prevalence.

The results of a meta-analysis of 121 studies conducted between 1962 and 2009 were published by the World Health Organization in six geographical regions (Asia, Europe, Africa, Latin America, North America and Australia). According to the report, the prevalence of vitamin D deficiency 
in the world (at a cut-off value of $30 \mathrm{ng} / \mathrm{mL}$ ) ranges from 2 to $97 \%$. Regionally, it is found that the severe deficiency is a more important problem in Asia (18 $48 \%$ ) and the Middle East (9 - $80 \%$ ) (Mithal et al., 2009).

As many studies exist in Turkey related to vit D levels containing children, adolescent, postmenapausal patients, we found no studies demonstrating the prevalence D deficiency.

In all studies, it is possible to reach the conclusion that vitamin $\mathrm{D}$ deficiency is more common in some regions but it is a worldwide health problem and affects the pregnant / newborn population more frequently (Mithal et al., 2009; Daphna, 2011; Rajneeta et al., 2016).

In our study, vitamin D insufficiency was found in $58.1 \%$ and severe deficiency was found in 36.9 $\%$. Normal vitamin D levels were detected in only 5 $\%$ of the patients. These data show that our threshold value and the proportion of studies conducted in our region are close to each other, and maternal vitamin $\mathrm{D}$ deficiency is a very important public health problem.

Geographical factors are very effective in vitamin D metabolism. Many factors affect the efficiency of the sun's rays, such as cloud density, ozone layer density, air pollution level, altitude, time / duration of sun exposure, and social clothing style. In the North American study, it has been shown that 5 to 15 minutes of sunshine everyotherday, face and arms exposed to the sun are important to meet the need for vitamin D (Hollick, 1996). On the one hand, modern business life, urbanization and industrialization are obstacles to the duration and quality of exposure to the sun. On the other hand, the conservative society that condemns women to their homes and the low socioeconomic level also affect the production of vitamin D in a poor way (Cidem et al., 2013).

In our study, the incidence of abnormal vitamin $\mathrm{D}$ in the urban and rural population was found to be close to each other $(94.6 \%-95.7 \%)$. There was no statistically significant correlation between the place of life and vitamin D levels $(\mathrm{p}=0.529)$. So that points out the importance of other contribiutor factors like personal factors.

Seasonal differences with geographical factors are also important. In the north and south of 33 degrees' latitude, it is shown that there is no vitamin D synthesis due to the oblique angle of incidence of sun rays in winter. The closer to the equator region, the seasonal difference disappear (Wacker and Holick, 2013). As in many studies, a recently published Chinese study has also shown that vitamin $\mathrm{D}$ deficiency is more frequent in winter and autumn (Yuan-Hua et al., 2018). In our study, we also tried to reveal the correlation between vitamin $\mathrm{D}$ and seasons. The incidence of vitamin D deficiency was as follows in the seasons; summer $89.4 \%$ - spring $93.3 \%$ - winter $98 \%$ - autumn $99.4 \%$. We have also found that vitamin $\mathrm{D}$ deficiency is seen higher in winter and autumn, as in other studies. $(p=0,000)$

Depending on personal factors such as dark skin pigmentation, advanced age (> 70), malabsorption (such as cystic fibrosis, Crohn's disease, gluten enteropathy), liver / kidney disease and topical sun cream (especially > 30 factors), vitamin D levels differ (Dror and Allen, 2010). We investigated the effect of age on vitamin D levels in our study. Vitamin D deficiency was found to be $95.8 \%$ in the $<35$ age group and $>90.9 \%$ in the 35 years' age group. Thus, in the $<35$ years' age group, we found significantly more vitamin $\mathrm{D}$ deficiency $(\mathrm{p}=0.03)$.

The review published in 2014 does not fully support routine vitamin D supplementation in pregnancy. It is argued that routine vitamin D monitoring in pregnancy is more accurate in providing support to patients with low levels (Weinert and Silveiro, 2015). In studies dealing with dietary regulation other than vitamin D support, it has been shown to be useful to question dietary habits and to take note of body mass index during early prenatal referral (Milman et al., 2016).

In addition, many organizations recommend routine vitamin D supplements without regard to vitamin $\mathrm{D}$ levels. The American College of Obstetricians and Gynecologists (ACOG), the Endocrine Society, and the Institute of Medicine (IOM) recommend $600 \mathrm{IU} /$ day vitamin D for pregnancy (Institute of Medicine, 2011; Holick et al., 2011; ACOG Committee on Obstetric Practice, 2011). In addition, the Nordic Council of Ministers (NORDEN) and the Scientific Advisory Committee on Nutrition (SACN) offer lower dose (400 IU / day) support (Nordic Council of Ministers, 2012; Scientific Advisory Committee on Nutrition, 2016). T. C. On May 2011, the Ministry of Health announced $1200 \mathrm{IU} /$ day vitamin D from the 12th week of pregnancy to the 6th month of postpartum in the 'Gebelere D Vitamine Support Program' report (Republic of Turkey Ministry of Health, 2011). In addition, IOM has been reported to be acceptable for vitamin D, with nontoxic dose of $4000 \mathrm{IU} /$ day (Institute of Medicine, 2011). According to a newly published metaanalysis that examines the preterm 
birth risk and newborn outcomes of vitamin supplementation, vitamin $\mathrm{D}$ levels $<30 \mathrm{ng} / \mathrm{mL}$ have an $11 \%$ increase in the risk of preterm labor. Vitamin D supplementation can reduce the risk of preterm labor and associated perinatal mortality (Amegah et al., 2017).

Because of the different measurement techniques used to measure vitamin D levels, it is difficult to define the threshold value for optimal bone health. For this reason, there is a need for work done with standard reference methods adapted to the whole world that can accurately and reliably measure 25 $\mathrm{OH} \mathrm{D}$ levels. Different definitions of deficiency and insufficiency in the literautre also makes it difficult to compare the vitamin D deficiency and insufficiency (Ruddersa and Camargo, 2015).

\section{Conclusion}

In our study, we observed that vit D deficiency which having maternal effects such as preclampsia, preterm labor, abortus, early osteoporosis and neonatal effects like rickets, tetany, hypocalcemic convulsions, congenital cataracts, and severe shortage, is in a high percentage in our society (95 $\%)$. Considering that this high prevalence is related to limited sunlight exposure and dietary factors, we suggest that dietary supplementation and vitamin D supplementation should be appropriate. In addition, the importance of sunbathing and patient education about dietary content can also contribute to treatment.

We concluded that in which ratio vit $\mathrm{D}$ treatment decreases perinatal and maternal adverse outcomes is to be evaluated with cross-sectional studies and if the results of that 6 years are positive, it would be improved by more effective methods by taking into consideration the age group, season and geographical region.
Ethics Committee Approval: Ethics committee approval was received for this study from Clinical Research Ethics Committee of Ordu University Medical Faculty.

Peer-review: Externally peer-reviewed.

Author Contributions: Concept-D.D.K.; DesignD.D.K.; Supervision- D.D.K.; Funding- D.D.K.; Materials- D.D.K.; Data Collection/Data ProcessD.D.K.; Analyze or Comment- D.D.K.; Literature Scanning- D.D.K.; Writer of Paper- D.D.K.; Critical Review- D.D.K.

Conflict of Interest: No conflict of interest was declared by the author.

Financial Disclosure: The author declared that this study hasn't received no financial support.

\section{References}

ACOG Committee on Obstetric Practice. Committee Opinion Number 495: Vitamin D: screening and supplementation during pregnancy. Obstetics and Gynecology 2011; 118:197-8.

Amegah AK, Klevor KK, Wagner CL. Maternal vitamin $\mathrm{D}$ insufficiency and risk of adverse pregnancy and birth outcomes: A systematic review and meta-analysis of longitudinal studies. PLOS ONE https://doi.org/10.1371/journal.pone.0173605 March 17,2017.

Barrett H, McElduff A. Vitamin D and pregnancy: An old problem revisited. Best Practice \& Research Clinical Endocrinology \& Metabolism 2010; 24:527-39.

Bikle DD. What's new in vitamin-D: 2006-2007. Current Opinion in Rheumatology 2007; 19:3838.

Cidem M, Kara S, Sarı H, Ozkaya M, Karacan I. Prevalence and risk factors of vitamin D deficiency in patients with widespread musculoskeletal pain. Journal of Clinical and Experimental Investigations 2013;4(4):488-91.

Daphna K. Vitamin D status during pregnancy: maternal, fetal, and postnatal outcomes. Current Opinion in Obstetrics and Gynecology 2011; 23:422-6.

Dror DK, Allen LH. Vitamin D inadequacy in pregnancy: biology, outcomes and interventions. Nutrition Reviews 2010; 68:465-77. 
Ferrari D, Lombardi G, Banfi G. Concerning the vitamin $D$ reference range: pre-analytical and analytical variability of vitamin D measurement. The journal of Croatian Society of Medical Biochemistry and Laboratory Medicine 2017;27(3):1-14.

Fidan F, Alkan BM, Tosun A. Pandemic Era: Vitamin D Deficiency and Insufficiency. Turkisch Journal of Osteoporosis 2014; 20:71-4.

Holick MF, Binkley NC, Bischoff-Ferrari HA, Gordon CM, Hanley DA, Heaney RP, et al. Evaluation, treatment, and prevention of vitamin D deficiency: An Endocrine Society clinical practice guideline. Journal of Clinical Endocrinology Metabolism 2011; 96:1911-30.

Holick MF. Vitamin D and bone health. The Journal of Nutrition 1996; 126:1159-64.

Institute of Medicine. Dietary reference intakes for calcium and vitamin D. Washington, DC: National Academies Press, 2011.

Iyidir OT, Altınova AE. Vitamin D and Diabetes Mellitus. Turkish Journal of Endocrinolgy and Metobolism 2012; 16:89-94.

Kent GN, Price RI, Gutteridge DH, Rosman KJ, Smith M, Allen JR, et al. The efficiency of intestinal calcium absorption is increased in late pregnancy but not in established lactation. Calcified Tissue International 1991; 48:293-5.

Kiely M, Hemmingway A, O'Callaghan KM. Vitamin $D$ in pregnancy: current perspectives and future directions. Therapeutic Advances in Musculoskeletal Disease 2017; 9(6) 145-154.

Kovacs CS, Kronenberg HM. Maternal-fetal calcium and bone metabolism during pregnancy, puerperium and lactation. Endocrine Reviews 1997; 18:832-72.

Kovacs CS, Kronenberg HM. Skeletal physiology: pregnancy and lactation. In: Favus MJ (ed). Primer on the Metabolic Bone Diseases and Disorders of Mineral Metabolism (6th ed). Washington, DC: American Society for Bone and Mineral Research 2006: 63-70.

Mallah EM, Hamad MF, Elmanaseer MA Qinna NA, Idkaidek NM, Arafat TA, Matalka TZ. Plasma concentrations of 25-hydroxyvitamin D among Jordanians: Effect of biological and habitual factors on vitamin D status. BMC Clinical Pathology 2011; 11:8:1-6.
Meer IM, Middelkoop BJC, Boeke AJP, Lips P. Prevalence of vitamin D deficiency among Turkish, Moroccan, Indian and sub-Sahara African populations in Europe and their countries of origin: an overview. Osteoporosis International 2011; 22:1009-21.

Milman N, Paszkowski T, Cetin I, Castelo-Branco C. Supplementation during pregnancy: beliefs and science. Gynecology and Endocrinology 2016;32(7):509-516.

Mithal A, Wahl DA, Bonjour JP Burckhardt P, Dawson-Hughes B, Eisman J. et, al. Global vitamin $\mathrm{D}$ status and determinants of hypovitaminosis D. Osteoporosis International 2009;20:1807-20.

Nordic Council of Ministers. Nordic nutrition recommendations: integrating nutrition and physical activity, 2012.

Pludowski P, Holick MF, Pilz S, Wagner CL, Hollis BW, Grant WB. et al. Vitamin D effects on musculoskeletal health, immunity, autoimmunity, cardiovascular disease, cancer, fertility, pregnancy, dementia and mortality-a review of recent evidence. Autoimmunity Reviews 2013; 12:976-89.

Rajneeta S, Susan MBM, Carlos AC, Cameron CG. Global summary of maternal and newborn vitamin D status-a systematic review. Maternal and Child Nutrition 2016; 12:647-68.

Republic of Turkey Ministry of Health. Vitamin D support program in pregnants, May 2011.

Ruddersa SA, Camargo CA. Sunlight, vitamin D and food allergy Current Opinion in Allergy and Clinical Immunology 2015;15:350-7.

Scientific Advisory Committee on Nutrition. Vitamin D and health. London: The Stationary Office, 2016.

Wacker M, Holick MF. Sunlight and Vitamin D: A global perspective for health. DermatoEndocrinology 2013; 5:51-108.

Weinert LS, Silveiro SP. Maternal-Fetal Impact of Vitamin D Deficiency: A Critical Review. Matern Child Health Journal 2015; 19:94-101.

Yuan-Hua C, Lin F, Jia-Hu, H Hua W, Cheng Z, Fang-Biao T. et al. Influent factors of gestational vitamin $\mathrm{D}$ deficiency and its relation to an increased risk of preterm delivery in Chinese population Scientific Reports 2018;8:3608:1-8 